-ns -

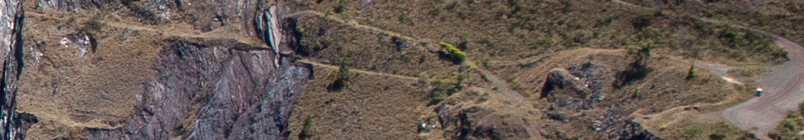

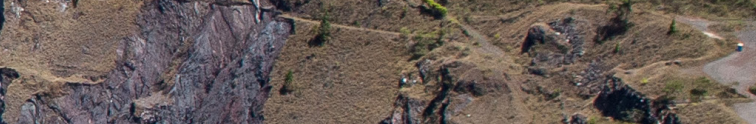

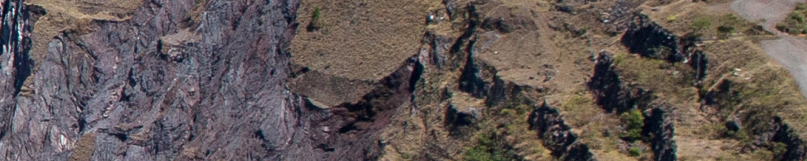

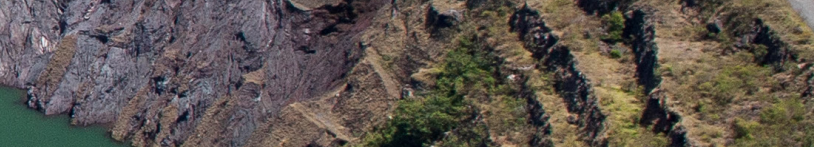

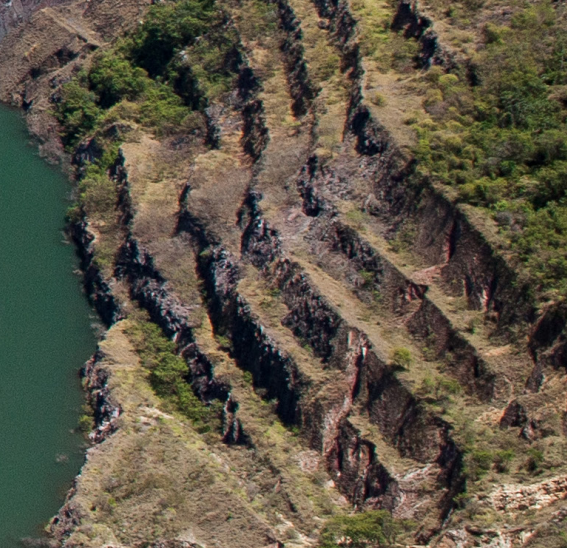




\section{PAISAGENS CULTURAIS DA MINERAÇÃO}

\section{Flavio de Lemos Carsalade}

Vice-presidente do Icomos-BRASIL. Presidente do Instituto Estadual do Patrimônio Histórico e Artístico de Minas Gerais (1999-2002) e Secretário Municipal de Administração Urbana Regional da Prefeitura de Belo Horizonte (2004-2007)

\section{RESUMO}

O trabalho analisa as interfaces existentes entre a atividade de mineração e o conceito de paisagem cultural, buscando compreender a dinâmica e a importância desse encontro para a formação e o futuro do Estado de Minas Gerais, Brasil. Examina ainda os impactos da atividade de mineração nessa paisagem hoje e a busca de alternativas para minimização de conseqüências negativas, à luz da História recente de Minas Gerais e de outras experiências internacionais.

Palavras chave: patrimônio cultural, paisagem cultural, mineração 
ID_PESQUISAS

\section{RESUMEN}

El articulo analiza las interfaces existentes entre la actividad de minería y el concepto de paisaje cultural, buscando comprender la dinámica y la importancia de ese encuentro para la formación y futuro del Estado de Minas Gerais, Brasil. Examina los impactos de la actividad minerária en esa paisaje hoy y la búsqueda de alternativas para la minimización de impactos negativos, a la luce de la Historia reciente de Minas Gerais e de otras experiencias internacionales.

Palabras clave: patrimonio cultural, paisaje cultural, minería

\section{ABSTRACT}

The article analyses the current interfaces between the mining activity and the concept of cultural landscape, in order to understand the dynamics and meaning of this encounter to the formation and future of the State of Minas Gerais/ Brasil. It exams the current impacts of the mining activity in this landscape and looks for alternatives to minimize negative consequences, inside the recent history of the State of Minas Gerais and other international experiences.

\section{Keywords: cultural heritage, cultural landscape, mining}




\section{PAISAGEM CULTURAL, TERRITÓRIO E PATRIMÔNIO}

O conceito de paisagem, conforme entendido em vários setores que sobre ele se debruçam, não exclui a participação do homem quer na sua produção, quer na sua percepção e valoração, caracterizando-a como um produto cultural e, como tal, dotada de valores e julgamentos sociais que sobre ela se produzem, em diferentes tempos. (CAUQUELIN, 2007). Nesse sentido, ela é formada pela cultura e desta também é formadora. Para esse entendimento contribuiu fortemente o trabalho de Carl Sauer no início do século XX, nos EUA, voltado para o método morfológico de análise da paisagem através do qual a paisagem se definiria por uma associação distinta de formas, tanto naturais como culturais, onde a cultura se apresentaria como agente, a área natural como meio e a paisagem cultural como resultado. Nossa abordagem do conceito de "paisagem cultural" ultrapassa as classificações de cenário pitoresco ou de caracterização geográfica e compreende qualquer paisagem que ganhe significado para o indivíduo e seu grupo cultural, seja ela natural ou construída, posto que é fundamental o entendimento das relações que se estabelecem entre ela e sua apreensão subjetiva ou melhor, intersubjetiva.

Na esteira dessas transformações científicas, o exame do conceito de paisagem pela área do patrimônio cultural faz constatar duas grandes ampliações no seu entendimento. No âmbito da UNESCO, a primeira delas ocorre na década de 1970, com a incorporação da vertente Patrimônio Natural e a outra em 1992 com a ampliação do conceito de Paisagem Cultural como resultado das interações significativas entre o homem e o meio ambiente natural (UNESCO, 1999). Embora a abordagem inicial dos anos setenta tivesse o grande mérito de tornar inseparáveis os bens naturais e os bens culturais, a dos anos 90 reduz seu espectro, ao parecer eleger como "Paisagem Cultural da Humanidade" apenas aquelas de transformação muito lenta ou que tem uma forte preponderância do ambiente natural.

O segundo conceito em exame, o de território, deve ser compreendido como uma porção físico-espacial que abarca relações socioeconômicas e culturais e com elas interage. O território é um lugar compartilhado no cotidiano, criador de raízes, laços de pertencimento e símbolos, mas que também reflete aspectos ideológicos, os quais lhes dão sentido e motivam seus movimentos internos, ou seja, segundo Ribeiro (RIBEIRO e MILANI, 2009), "o território é um espaço de construção social, política, econômica e simbólica". Revela as relações de poder, quer do Estado, quer de grupos dominantes, o que o configura como espaço 
de lutas sociais cotidianas e em constante transformação. A dinâmica e a transformação são, portanto, duas de suas características intrínsecas. O território representa, assim, as relações sociais no espaço.

Da análise acima, torna-se evidente a confluência dos dois conceitos. Embora o primeiro - paisagem cultural - se volte mais para os aspectos simbólicos (culturais) e o segundo território - para a apropriação e relações que aí se exercem (socioeconômicos), ambos se unem - e se complementam - no entendimento da ação antrópica sobre a natureza para torná-la o locus da cultura e da apropriação das sociedades humanas. Não há, portanto, a nosso ver, porque separar os dois conceitos quando se trata de uma análise que se pretende integradora e que não desvincule a cultura dos outros campos de ação humana sobre a realidade (CARSALADE, 2005).

\section{2. ÁREAS MINERADAS E PATRIMÔNIO}

O patrimônio cultural apresenta várias escalas porque também são várias as escalas dos objetos portadores de significados especiais. A complexidade no trato desses objetos, embora sempre grande e com problemas específicos pertinentes a cada uma dessas escalas, parece se multiplicar com o aumento de escala e, assim, se já se apresentava dificuldades especiais de gestão no caso de núcleos urbanos protegidos pelo tombamento, por exemplo, quando nos deslocamos para a escala regional - que, grande parte das vezes é a escala da paisagem - as questões epistemológicas e metodológicas também ganham outra dimensão e especificidade.

Um bom exemplo dos agentes transformadores que atuam na paisagem são exatamente as atividades de grande porte, pois além das alterações físicas, pelo poder econômico que representam e por sua escala, possuem um considerável potencial indutor de alterações também das relações territoriais. A mineração é um representante bem característico desses agentes, especialmente aquelas minas a céu aberto, não só pelas cicatrizes que criam, mas também por trazerem consigo a problemática dos rejeitos e seus amplos depósitos. Além disso, no plano socioeconômico-cultural, este é completamente modificado pela força da atividade e seus impactos nas populações locais afetadas. 
Um exemplo típico desses impactos no caso brasileiro é a condição relacional que as empresas criam com as sociedades e os locais onde se instalam. Na maioria das vezes elas se apresentam como enclaves dissociados do seu território, reforçando uma posição de autonomia e provocando tanto processos de exclusão como de desterritorialização, agravados pelas relações internacionais de mercado para as quais as mineradoras têm se voltado quase exclusivamente. As áreas mineradas são fortemente protegidas, muitas vezes ocultadas e, embora haja uma relação com as comunidades de entorno, essas relações são marcadas mais por aquelas ações que as empresas entendem que, a seu juízo, são interessantes para a imagem e para a aceitação delas próprias, do que efetivamente pela consideração dos movimentos populares, por motivações de planejamento urbano ou por diretrizes de patrimônio cultural. É assim que desse contexto, emergem três tipos de impactos que marcam bastante a atividade: a escala desses impactos, a "exclusão" territorial e a preocupação em apenas recompor o meio-ambiente na estrita acepção da lei.

Considerando a escala de seus impactos, o resultado com relação às paisagens tem sido, por via de regra, de devastação, nela incluindo aspectos de poluição do meio ambiente, quer no processo exploratório das minas quer no pós-fechamento. A recuperação ambiental e a recomposição da paisagem não implicam o retorno à sua configuração original, de resto uma impossibilidade prática. Mas é possível considerar, na perspectiva de criação de novas paisagens, o estabelecimento de bases consensuais e socialmente construídas.

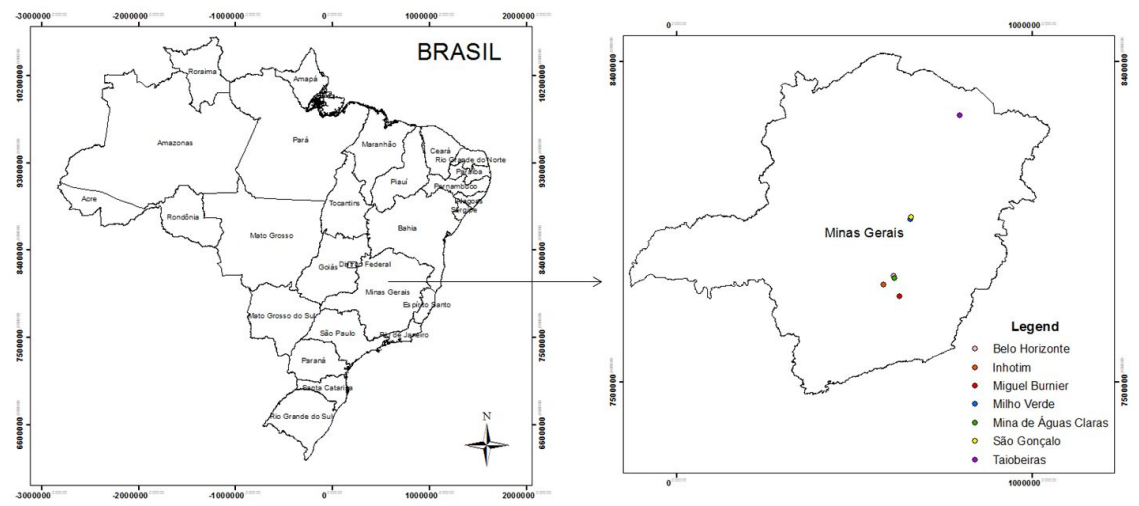


Nesse sentido, a estrita observância legal não é suficiente para solucionar o problema da recomposição da paisagem, porque não se trata apenas da consideração de um recorte territorial que receberá novos usos, mas também das relações socioculturais nela inseridas e dela decorrentes. Com isso, tanto as formas de exploração mineral como os planos e as ações de recuperação e recomposição têm expressado atitudes de deliberada exclusão territorial.

\section{ALGUNS EXEMPLOS INTERNACIONAIS E DE MINAS GERAIS}

Para que se obtenha um panorama internacional do problema, examinaremos a seguir um caso europeu e outro latino americano para, a seguir, apresentarmos a situação do Estado de Minas Gerais, o maior Estado minerador da federação brasileira e que apresenta uma gama variada de situações, como teremos oportunidade de exemplificar.

\subsection{Nord-Pas-de Calais, França}

PaA história recente da região francesa de Nord-Pas-de-Calais gira em torno da mineração de carvão, seja na sua fase de apogeu a partir da segunda metade do Século XIX, seja a partir dos efeitos causados pelo seu declínio, 150 anos depois. A nova organização territorial derivada do período pós-exploratório (iniciado em 1984) é caracterizada por um espaço fortemente urbanizado, densamente povoado, polarizado por diferentes minas, mas desprovido de uma centralidade real.

O enorme passivo de estruturas abandonadas, a poluição dos solos, a decadência econômica regional, desemprego e problemas habitacionais foram desafios que tiveram de ser enfrentados em uma trama urbana inteiramente voltada para a atividade minerária e que se apresentava perpassada por vazios caracterizados pela presença de edifícios industriais desativados e por uma forte poluição residual. A interrupção da atividade ensejou o aparecimento de um desemprego em massa, da degradação do habitat tradicional dos mineiros (as cidades minerárias) e de um problema geral de atratividade territorial, com uma grande dificuldade na emersão de novas centralidades urbanas e uma dificuldade de integração com a Região Metropolitana de Lille. No caso de Nord-Pas-de-Calais, a questão da paisagem cultural associada ao potencial deixado pela atividade minerária foi decisiva

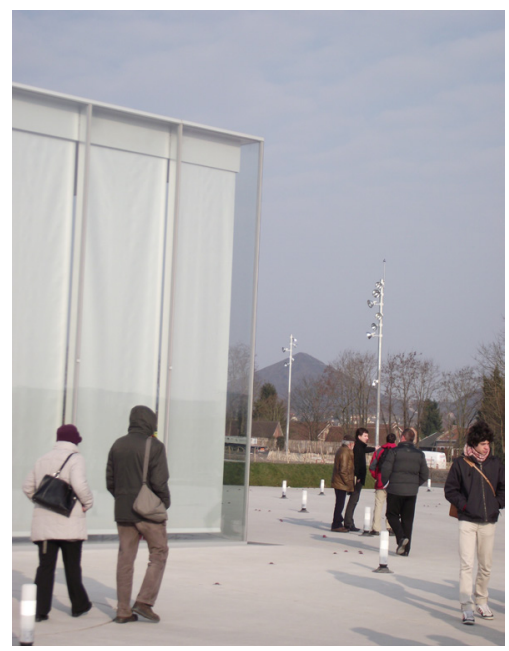

Louvre Lens com pilha de rejeitos de mineração ao fundo na região de Nord-Pas-de-Calais, França Fonte: Flavio Carsalade. 
para o novo ciclo criativo, o qual, no entanto, não ocorreria não fosse a forte presença do Estado combinada com a participação das comunidades, através das seguintes ações:

- Deslocamento da titularidade fundiária para o setor público com forte indução das coletividades locais a reabilitar seus baldios industriários com o apoio do Etablissement Public Foncier du NPDC (Instituto Fundiário Público de NPDC, criado em 1990);

- A candidatura a patrimônio mundial da bacia minerária de NPDC como paisagem cultural evolutiva de valor excepcional e universal, efetivada em 2012 pela UNESCO, considerada como uma estrutura orgânica global que se distingue por sua continuidade e sua homogeneidade e não como uma coleção de sítios ou de monumentos individuais;

- A atração de grandes equipamentos culturais para a região, como uma "filial" do Museu do Louvre na cidade de Lens, com três estratégias bem claras: a transformação física do lugar com renovação urbana; a renovação econômica com base no turismo e na cultura e o desenvolvimento de cinco " clusters » econômicos (setores de logística, eco-materiais, economia do esporte e produção cultural/ centros de arte).

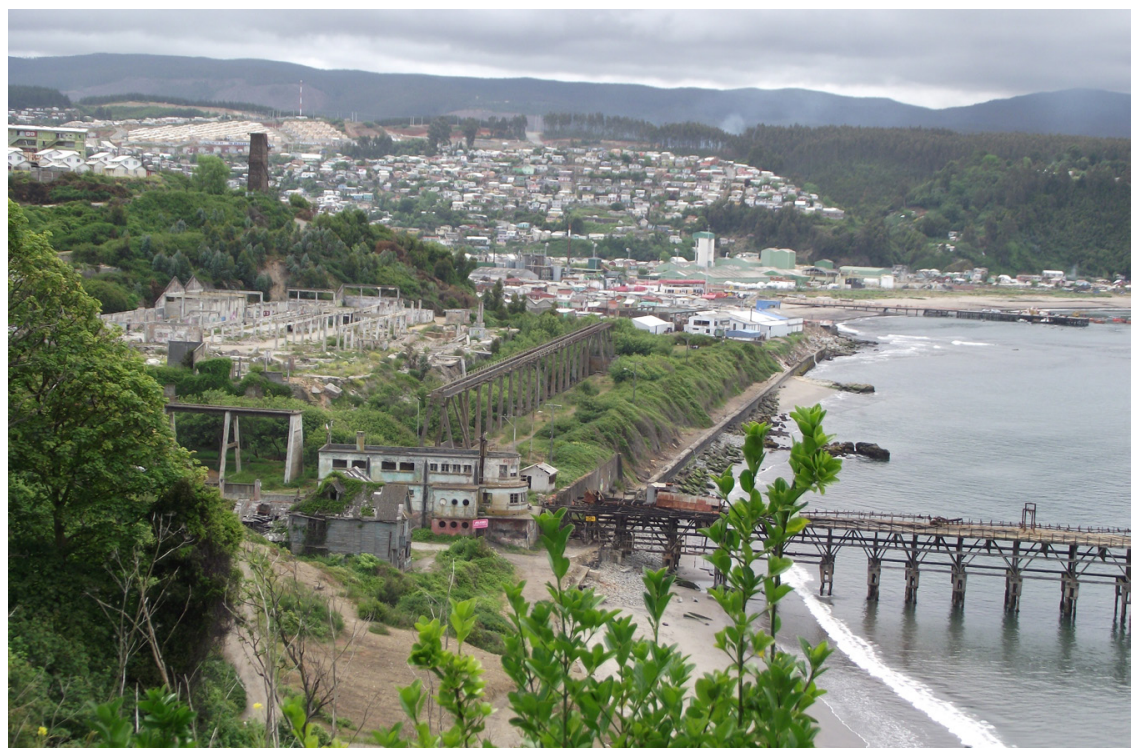




\subsection{Lota, Chile}

O Chile é um país de grande tradição minerária na América do Sul. Sua produção mais expressiva se encontra na exploração do Cobre e do salitre, mas também a produção carbonífera, mais ao sul do país, teve grande importância histórica e econômica. Com o fim da exploração do carvão em 1997 nas cidades de Lota e Coronel, restaram problemas muito parecidos com os das Região de Nord Pas-de-Calais: um grande patrimônio industrial sem uso e o problema da decadência econômica local. As buscas de alternativas para soluções desses problemas vieram nem tanto dos governos locais, mas principalmente do Governo Federal, que já tivera êxito com o reconhecimento de Humberstone e Santa Laura como Patrimônio Mundial em 1971. Assim, através da titulação de Lota e Coronel na categoria de Monumento Nacional, o Governo Federal passou a executar algumas ações de proteção, restauração e gestão, especialmente através de três ações: o Plano Integral de Desenvolvimento de Lota, orientado a facilitar o processo de transformação produtiva local (1997 - 2000), o Plano de Desenvolvimento Territorial (PDT) para o Territorio de Reconversão (2004 y 2006 e o Programa Bicentenario; programa nacional de celebração. Embora os planos não apresentassem resultados significativos, eles apresentaram vários ganhos metodológicos, especialmente quanto á reflexão sobre técnicas e procedimentos quanto à recuperação das paisagens culturais em territórios pós-minerados. Tanto é assim que, desde 2012, se encontra em trâmite estudos para modificar o Plano Regulador Comunal (PRC), o qual seleciona e analisa diversos elementos do patrimônio construído, para possibilitar sua recuperação. Do ponto de vista econômico, as ações ficaram localizadas na área do turismo, embora a recuperação ambiental de extensas áreas particulares tenha se agregado ao sistema de parques e espaços públicos da cidade.

\subsection{Minas Gerais}

O Estado de Minas Gerais evidencia, em seu próprio nome, a importância histórica da mineração, que foi o principal motor de desencadeamento da ocupação de seu território, no período colonial e segue sendo importante atividade econômica em várias regiões do Estado, motivadora de desenvolvimento e transformações sociais em todo ele. Foram as expectativas de existência de riquezas minerais que motivaram as "entradas e bandeiras" exploratórias 


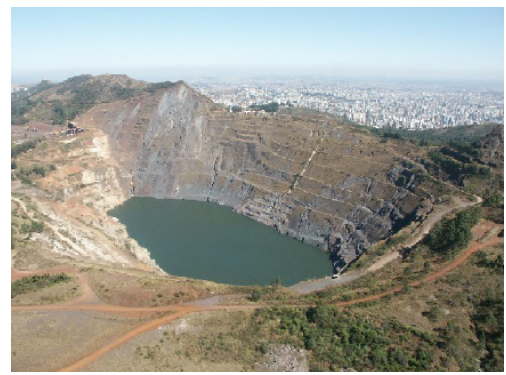

Cava da Mina de Águas Claras, em processo de enchimento. Ao fundo, Belo Horizonte e à esquerda, o Pico do Patrimônio. Fonte: BRASIL; MINAS GERAIS, 2005.

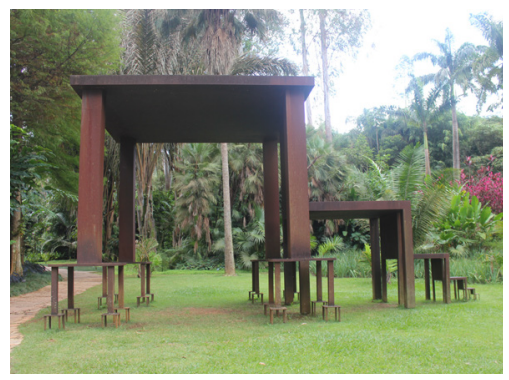

Inhotim, Região Metropolitana de Belo Horizonte Fonte: Renata Castro. do interior do país no século XVII e a atração de um expressivo fluxo migratório após sua confirmação no Século VIII. Preteridos pela colonização inicial do Brasil, os territórios do interior de Minas Gerais viram surgir, pela força atratora da mineração, inúmeros assentamentos humanos, que logo se converteram em povoações permanentes, rapidamente constituindo sociedades complexas com alta qualidade artístico-cultural, derivadas exatamente da diversidade étnica e das realidades políticas e religiosas que foram sendo construídas.

Também a evolução da mineração no século XIX, agora com a presença de outros metais, notadamente o ferro, foi responsável pela criação de outras tantas localidades, algumas delas de importância singular e também patrimônios estaduais e nacionais. Nem mesmo a produção cafeeira, a partir da segunda metade do mesmo século XIX, chegou a abalar a forte presença formadora da mineração em Minas Gerais.

A importância da mineração, como dito, se espalha por todo o Estado de Minas, na Zona da Mata com as reservas de bauxita, no centro-norte, região de Araxá, com as reservas de Nióbio, de grafita em Salto da Divisa, de ouro nas proximidades com Goiás e na região de Nova Lima, de pedras preciosas e semipreciosas no Vale do Jequitinhonha e do Mucuri, Governador Valadares e Teófilo Otoni, todas elas formadoras, tanto no passado quanto no presente, das localidades onde se situam, como se demonstra desde a presença fundante dos ingleses em Nova Lima, das civilizações geradas na região do Serro e Diamantina pela presença do diamante ou da macrorregião em torno de Ouro Preto (hoje exploradas também pela "segunda safra" do turismo) até as expectativas futuras dos impactos que podem ocorrer no Norte de Minas com a anunciada exploração mineral em Grão-Mogol, Salinas, Taiobeiras e vizinhança.

\subsection{1. Águas Claras}

A Mina de Águas Claras se instala na porção mais simbólica de Belo Horizonte, a Serra do Curral. Trata-se de uma mineração de ferro a céu aberto que funciona a mais de cinquenta anos e que, desde então vem gerando uma série de impactos na paisagem, desde a supressão significativa da linha de cumeada da Serra até a criação de uma enorme cava na sua porção sul. É um enclave significativo na Região Metropolitana de belo Horizonte extamente na divisa entre dois de seus principais municípios, a capital e a cidade de Nova Lima. 
O enclave da mineração nesse local é preocupante pelos efeitos que pode gerar no território da RMBH em sua região ambientalmente mais sensível, pois é também aí que se situam importantes reservatórios de água que abastecem Belo Horizonte e grandes reservas florestais, remanescentes da mata atlântica, mas ao mesmo tempo, se dirigida corretamente com a participação do poder público e de interesses mais nobres, pode ser muito importante para a RMBH. No entanto, não parece ser esta a preocupação dos empreendedores que, ao se tornarem proprietários das terras mineradas, as vêem como possibilidade de lucrativo empreendimento imobiliário voltado para as populações de renda mais alta.

\subsubsection{Inhotim}

O caso de Inhotim, instalado em uma região de intensa atividade minerada, surge como uma alternativa interessante de requalificação de regiões degradadas pela mineração. Trata-se de um território de aproximadamente $97 \mathrm{Ha}$, totalmente dedicado à exposição de obras de arte contemporâneas e a grandes instalações artísticas, todas em meio a uma composição paisagística cuidadosamente planejada, inspirada, nos seus primórdios, em diretrizes oferecidas por Roberto Burle-Marx. É um empreendimento totalmente privado, fruto da atitude visionária de Bernardo Paz, dono das terras, financiador do projeto inicial e seu principal curador. Aí se encontram obras de artistas importantes como Helio Oiticica, Lygia Clark, Tunga, Adriana Varejão, Olafur Eliasson, dentre vários outros, em um acervo que cresce ano a ano, em meio a diferentes projetos de estímulo às artes. Tornou-se destino turísitco prefernecial na Região Metropolitana de Belo Horizonte por sua unicidade e inovação, mas sofre críticas contundentes quanto ao seu caráter excludente da população local e de mais baixa renda.

\subsubsection{Milho Verde e São Gonçalo do Rio das Pedras}

Milho Verde e São Gonçalo do Rio das Pedras são distritos do município do Serro, vizinho da cidade de Diamantina, Patrimônio Cultural da Humanidade. Foram grandes produtores de diamantes nos séculos XVII e XVIII, mas desde o fim da mineração ficaram economicamente estagnadas até serem redescobertas pelo turismo nas últimas décadas do 
século XX. Nesse Distrito Diamantino, as duas localidades, que distam $5 \mathrm{Km}$ uma da outra, tiveram importância estratégica. A primeira, Milho Verde, era o entreposto tropeiro e sede do quartel, e a segunda, São Gonçalo do Rio das Pedras, chegou a ser sede da Intendência dos Diamantes, órgão responsável pela administração do Distrito.

Ao fim do ciclo da mineração, elas apresentavam paisagens bem distintas. As paisagens de Milho Verde revelavam um núcleo urbano degradado, uma economia enfraquecida, baixos indicadores de qualidade de vida da população, concentração de terras, uma pecuária extensiva que substituía os campos por pastagens, e a maioria dos habitantes ocupada em atividades de subsistência. Já São Gonçalo emergiu do período diamantino com paisagens predominantemente mais qualificadas, caracterizadas por uma ocupação urbana com boa qualidade ambiental, uma população sobrevivendo de outras atividades produtivas, cursos d'água preservados, um ambiente rural que mantinha quase intactos os campos de cerrado e os remanescentes de Mata Atlântica, dentre outros aspectos positivos.

A redescoberta das duas localidades pelo turismo ao final dos anos 1970 encontrou um patrimônio preservado pela estagnação econômica, mas teve resultados diferentes em cada uma das duas. As atrações naturais de Milho Verde atraíram um público diversificado, mais efêmero em seus padrões de consumo e com menor relação com a terra, enquanto São Gonçalo atraiu aqueles que buscavam a tranquilidade e as possibilidades de experimentar o cotidiano e a qualidade dos espaços livres e edificados. Estes diferentes tipos de apropriação geraram impactos diferenciados, fazendo com que Milho Verde é resistente a qualquer controle e sujeita a forças especulativas tanto no comercio quanto no setor imobiliário, enquanto em São Gonçalo a atividade turística, mais controlada, tem apresentado mais resultados positivos do que negativos.

\subsubsection{Miguel Burnier}

Miguel Burnier é um distrito localizado na porção oeste do Município de Ouro Preto, parte integrante do Quadrilátero Ferrífero do Estado de Minas Gerais, cuja paisagem vem sendo modificada desde o século XIX devido às ações antrópicas relacionadas à exploração dos recursos naturais locais com finalidade minerária e industrial. E apesar de tal localidade ter passado por um período de crescimento econômico que durou até o quartel final do séc. 
XX, sua situação atual é de extremo estresse social, percebido tanto pelo processo de degradação do seu meio urbano quanto pelo êxodo da população local, que sai em busca de postos de trabalho e melhores oportunidades em outras localidades. Após algumas décadas de declínio da atividade minerária no local, a sua retomada recente se deu em outras bases, menos civilizatórias, excludente da paisagem e dos moradores locais, de forma mais predatória.

Assim, dicotomicamente, as atividades de exploração mineral no distrito em questão, presentes desde os primórdios de sua formação, contribuem para o processo de degradação socioambiental pelo qual o mesmo vem passando, ao mesmo tempo, que é também responsável pela constituição de um lugar social de memória, identidade e configurador do seu território, situação bastante comum no Estado de Minas Gerais.

\subsubsection{Norte de Minas Gerais}

O Norte de Minas Gerais está prestes a receber empreendimentos mineradores que implicarão, em um futuro bastante próximo, uma nova organização na rede urbana, com transformações tanto no território quanto na paisagem cultural da região. Embora os quatro empreendimentos principais ainda não tenham iniciado suas operações e os estudos de impacto não terem ainda sido apresentados, torna-se bastante especulativa a indicação de cenários futuros, seja em seus impactos positivos seja negativo. De concreto sobre as atividades mineradoras a serem, possivelmente, implantadas, destacamos que, em plena época de crise hídrica, já foram iniciadas as obras de construção do mineroduto, que escoará a produção de minério de ferro de dois dos quatro empreendimentos mencionados, até o porto de llhéus, impactando, ao longo de seus 480 km de extensão, 21 municípios nos estados de Minas Gerais e Bahia.

Em uma primeira abordagem, pode-se dizer que a identidade cultural regional foi determinada, pelo menos em parte, por uma situação de isolamento, realidade que somente começou a ser alterada a partir do final da década de 1980, com o asfaltamento do trecho da BR-251, de Salinas a Montes Claros, e à BR-116 (Rio-Bahia). Esse "isolamento" foi determinante nas relações sociais, econômicas e de consumo. Até então, o êxodo rural ocorria em um ritmo mais lento que no restante do país, influenciando no predomínio da economia 
agropecuária e no pequeno crescimento econômico. Com isso, uma característica forte que se desenvolveu, e que permanece até hoje, foi a presença dos mercados municipais e das feiras livres, os quais se tornaram os principais ícones da identidade cultural microrregional, em seu papel de local onde campo e cidade se encontram.

Ainda é prematuro indicar consequências da atividade minerária, mas alguns cenários já se delineiam, como a possível inversão entre os papéis de campo e cidade, transformando sensivelmente a paisagem hoje existente.

\section{O CASO DO QUADRILÁTERO FERRÍFERO EM MINAS GERAIS}

\subsection{Histórico}

Atualmente, a região do Quadrilátero Ferrífero, localizada no centro-sudeste do estado de Minas Gerais é considerada o território de maior concentração de minas em operação no mundo. Trata-se de uma porção de território de $7.000 \mathrm{~km} 2$ que tem como vértices as cidades de Itabira, a nordeste, Mariana, a sudeste, Congonhas, a sudoeste e Itaúna, a noroeste; e sua área compreende a capital do Estado, Belo Horizonte, além de várias cidades originadas da atividade minerária, dentre elas Nova Lima, Sabará, Santa Bárbara, Itabirito e Ouro Preto (RUCHKYS, 2007, p.44). Dentre suas riquezas minerais, destacamse o ouro, o ferro e o manganês, além dos tipos litológicos de grande relevância científica. Tal característica da região, por sua vez, proporcionou que a exploração de seus recursos minerários fosse o principal motor de desencadeamento da ocupação humana em seu território (GEOPARK, 2011).

As descobertas e uma série de expedições que se seguiram prepararam a grande fase das explorações auríferas e o povoamento do QF [Quadrilátero Ferrífero] com a fundação, em 1711, das vilas de Mariana, Vila Rica de Ouro Preto e Vila Real de Sabará. Vários arraiais e vilas dentro ou próximo do QF tiveram sua origem ligada à mineração do ouro, destacando-se, dentre outros: Caeté, Congonhas, Catas Altas, Santa Bárbara, Barão de Cocais, Cachoeira do Campo, Ouro branco, Nova Lima, São Gonçalo do Rio Acima e Piedade do Paraopeba. (RUCHKYS, 2007, p.58). Assim, além de uma ocupação territorial mais extensiva na região, presenciou-se o surgimento de uma rede de ocupação urbana 
composta por pequenos núcleos dispersos pelo território, que, por sua vez, converteramse em povoações permanentes rapidamente, constituindo sociedades caracterizadas pela diversidade étnica e alta qualidade artístico-cultural (MORAES, 2006).

As técnicas abordadas, no entanto, eram rudimentares, não apresentando meios de aprofundar a tecnologia de exploração na época. Com isto - e com o esgotamento das reservas auríferas mais superficiais, a partir da segunda metade do século XVIII - a população residente nos núcleos urbanos do Quadrilátero Ferrífero passou a se dedicar a outras atividades econômicas, como a agricultura e o comércio.

Desta etapa de povoamento, ressalta-se muito o expressivo patrimônio cultural resultante, cujas transformações verificadas nos tecidos urbanos das cidades setecentistas têm sido reconhecidas e valorizadas nacional e internacionalmente, principalmente quando falamos da Arte Barroca, cujo estilo repercutiu na arquitetura, nas artes plásticas, na música e na literatura (CARSALADE et $\mathrm{Al}, 2012$ ). As atividades extrativistas desenvolvidas durante o Período Colonial foram o embrião para a fase subseqüente, já no Período Imperial brasileiro, relacionadas à exploração do ferro. É durante o séc. XIX que começamos a perceber a tímida introdução da mecanização na economia do Quadrilátero Ferrífero, caracterizando, o início do período dominado pelos meios técnicos. Assim, nas primeiras décadas do séc. XIX, vemos serem estabelecidas no território do Quadrilátero Ferrífero, duas, das três primeiras usinas siderúrgicas brasileiras: a Usina do Morro do Pilar, fundada por Manoel Ferreira da Câmara, em 1808 e a Fábrica Patriótica, fundada em Congonhas por Eschwege, em 1812. Também no Século XIX, no setor aurífero, várias empresas com capital inglês passaram a explorar em larga escala o ouro brasileiro.

No entanto, apesar de todas as inovações tecnológicas, a exploração de ouro no Brasil entrou em queda, uma vez que não se pode deixar de ressaltar que, por essa mesma época, a lavoura cafeeira passou a ser a preocupação central do governo Imperial, uma vez que a mesma já despontava como principal produto das exportações brasileiras. Além disso, em âmbito internacional, o ouro brasileiro perdeu destaque pela descoberta de ouro em outros países como os EUA (1848), Austrália (1851), África do Sul (1886) e Alasca (1896) (RUCHKYS, 2007, p.62). 
No período compreendido entre o final do séc. XIX e começo do séc. $X X$, a implantação da malha ferroviária nacional constituiu-se em outro fenômeno transformador do espaço nacional, assim como do território do Quadrilátero Ferrífero. As ferrovias foram responsáveis pelo desenvolvimento de regiões distantes e inexploradas do país, favorecendo a circulação de bens e pessoas e o surgimento de povoações e cidades ao longo de seu trajeto. Para o caso de Minas Gerais, estas traziam uma maior integração com os dois centros mais importantes da época: a Capital do Estado, Rio de Janeiro; e São Paulo, a região mais industrializada do país.

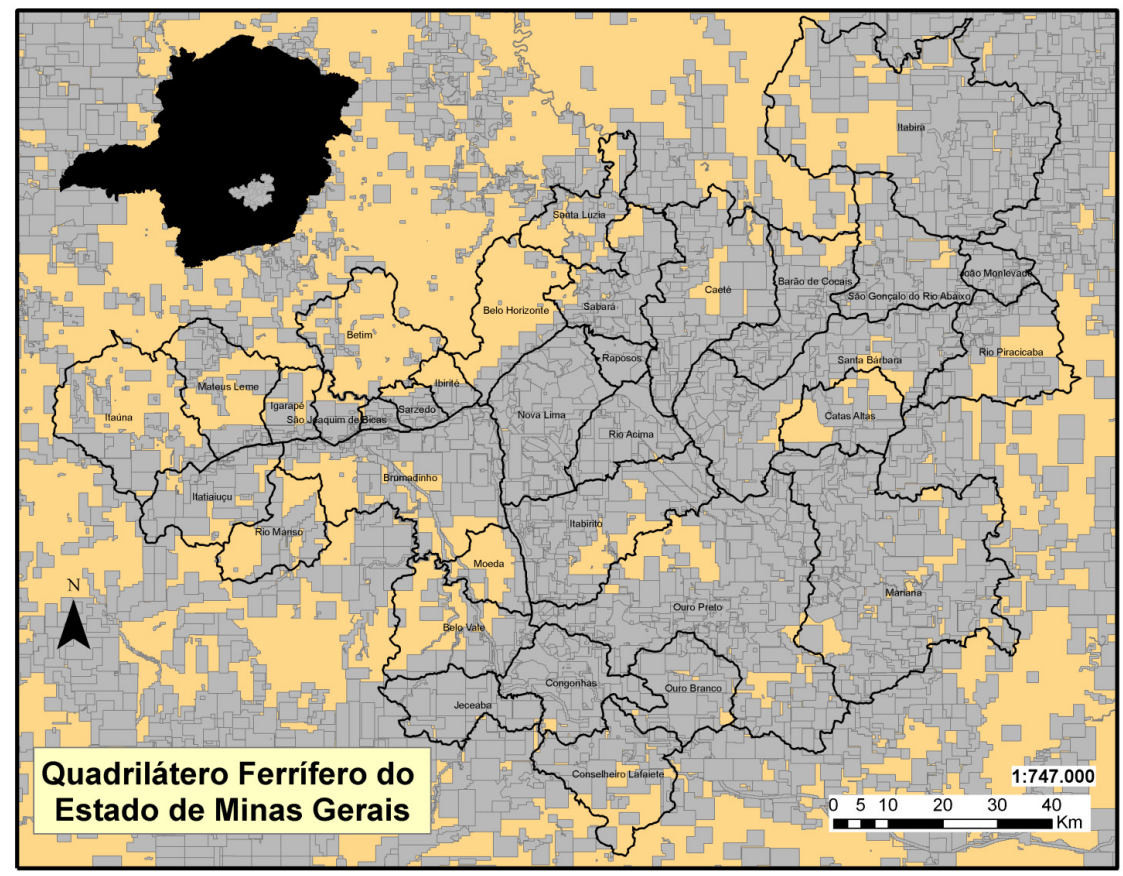


Mais propriamente sobre as marcas da indústria do ferro no território do Quadrilátero Ferrífero, podemos dizer que ainda há certa precariedade no mapeamento de sítios e estruturas desta época, que acarreta uma conseqüente falta de percepção de seus impactos na arquitetura e urbanismo locais, principalmente, se o compararmos com os estudos sobre os desdobramentos do período da exploração aurífera.

As diversas fases mineiro-industriais pelas quais passaram o território em questão também são promotoras de transformações na ambiência paisagística local, desta vez, bem mais expressivas em termos de consumo do espaço e de seus recursos naturais, do que o período anterior. Ainda, destacamos a questão dos aspectos sociológicos, nitidamente mais marcantes e persistentes entre as populações que habitam o território do Quadrilátero Ferrífero, responsáveis pela formação de um lugar social de memória, de identidade regional e configurador de uma percepção territorial própria, características estas, que se apresentam materializadas na configuração paisagística das localidades minerárias industriais.

\subsection{A criação do Geopark Quadrilátero Ferrífero como alternativa.}

Conforme vimos, a exploração mineraria no Brasil apresenta vários problemas, especialmente no que tange às dimensões da sustentabilidade e quanto às relações com o universo social e cultural onde se instalam. Em estados da federação como Minas Gerais, que responde por mais de $45 \%$ do produto mineral nacional, e onde a cadeia produtiva mineral responde por mais de $35 \%$ do PIB do Estado, temos como conseqüência um poder político demasiadamente forte em favor do poder de barganha da atividade minerária. Os governos estaduais e municipais se vêm tironeados entre duas ações iguais e contrárias, uma de origem econômica representada pelos interesses das empresas mineradoras e seus conselhos não muito dispostos a fazer concessões - embora adotem o discurso da preocupação ambiental - e outro de origem social, representada principalmente por seus setores organizados, sob a bandeira da defesa do meio ambiente e dos grupos sociais mais vulneráveis afetados pelas ações mineradoras.

De fato, na maioria das vezes, quando os interesses minerários identificam jazidas de alto interesse econômico, a sua ação é no sentido de criar estratégias para a sua exploração, independentemente de sua localização - se em locais ambientalmente sensíveis ou 
culturalmente ricos - ou das relações que essas possíveis minas tenham com as sociedades circundantes. A lógica metodológica de licenciamentos baseada em Estudos de Impactos Ambientais e uma legislação baseada em mitigações desses impactos e compensações ambientais leva a uma prática que permite vislumbrar qualquer lugar como passível de minerar desde que haja uma negociação bem feita. Essas negociações, caso a caso, são mais ou menos tensas dependendo da vulnerabilidade ambiental e social dos lugares, mas são considerados normais no processo, quase como passos "naturais" a seguir. A mesma lógica pressupõe que as "compensações" ou os "efeitos mitigadores de impactos" serão sempre suficientes ou para restituir os potenciais paisagísticos e ambientais das áreas mineradas ou para substituí-los por algo melhor, mais "útil" à sociedade. O conceito de "jogo de licenciamento" é, assim, centrado nos atores e, como um negócio, já pressupõe que trocas existirão e concessões deverão ser feitas, mas como todo bom negócio, estas deverão ser vantajosas para o melhor negociador. Intermediando as duas forças negociadoras - as empresas mieradoras e os grupos sociais - surge o governo, sem organização suficiente, também pressionado pela necessidade dos recursos e a de outros benefícios sociais (como geração de emprego e riqueza momentânea de seus âmbitos locais), atuando sob uma base legal que apenas legitima as regras do jogo.

Uma análise mais abrangente do problema parece nos levar a conclusões sobre a necessidade de se pensar a questão não apenas no "caso a caso" que hoje se verifica e em regras de relações que só se exercem nesses momentos, mas de uma forma que seja mais interessante para a sociedade como um todo e que envolvam por um lado, uma visão de futuro com planejamento, metas sociais e inclusão em planos integrados de desenvolvimento territorial e, por outro lado, um equilíbrio maior entre os jogadores, com empoderamento social e maior realismo com os atributos insubstituíveis de certo lugar. Dentro dessas novas possibilidades de trato da questão, nos parece estar duas ações fundamentais que são o zoneamento de áreas para mineração e novas formas de articulação entre os agentes nos territórios de mineração.

Se há uma característica que comum a essas duas formas é a noção de atuação sistêmica, em rede e em temporalidades específicas, a qual já vem se apresentando na agenda da empresa mineradora - hoje formadas não mais pelo pequeno explorador de uma mina só, mas por grandes empresas responsáveis por várias minas - que deixaram de tratar 
isoladamente o problema de cada uma delas, mas que vêem cada uma dessas minas como peças de um grupo maior, devendo funcionar integradas. Os minerodutos e o interesse pela malha ferroviária pré-existente são exemplos concretos desse novo tipo de estratégia, bem como outro, este mais perverso, que é o prolongamento excessivo de vida das minas, postergando-se o seu fechamento - e as conseqüentes e custosas ações mitigadoras e compensadoras. Já há, no jargão da área, até um nome para estas: as "minas-vagalume", por funcionarem intermitentemente, de forma a postergar a medidas custosas de fechamento de mina. A idéia empresarial de funcionamento em rede, infelizmente não trata essas redes em suas correlações territoriais na sua acepção mais ampla, de inclusão de agentes e do substrato físico onde se localizam, mas as entende apenas como um sistema fechado em suas relações de produção internas. Parece-nos óbvio que o interesse social mais amplo deveria combinar as ações estratégicas empresariais em rede com as ações de desenvolvimento estratégico da sociedade como um todo que, como sabemos, não prescinde de suas bases territoriais.

Ora, uma atuação em rede necessita muito de uma sinergia entre governo, sociedade e relações de produção. Sabemos que essa sinergia não existe nem no próprio governo, onde os seus setores temáticos de administração não conversam entre si, onde os processos pelas autorizações de pesquisa e lavra são muitas vezes imprecisos e com várias superposições e onde a participação social não é prática muito comum nas diferentes administrações seja em entes federativos diferentes (que mais das vezes são desarticulados), seja em diferentes períodos de tempo, onde se sucedem governos populares e liberais. Pode se atribuir a essa prática razões de ordem complexa - o mundo atual apresenta variáveis de toda ordem com inter-relações múltiplas - ou de ordem organizacional - diversidade de gestores, organização em conselhos temáticos, pactos setoriais. Assim, qualquer que seja a razão para a ausência de sinergia, percebe-se a necessidade de criação de formas alternativas de articulação social que, no mesmo nível da complexidade múltipla contemporânea possam interagir, a partir de uma tese de que a crise da governança pode se derivar da a crise da participação social.

É nessa raia que pretende agir o GEOPARK QUADRILÁTERO FERRÍFERO, sabedor que não se compreende mais, na contemporaneidade, áreas reservadas que não interajam com a sociedade ou que se constituam como ilhas alheias ao mundo lá fora. Trata-se de uma preocupação muito parecida com aquela que motivou os museus, em sua evolução, 
a perceber que tão importante quanto guardar acervos era a sua função como formadores de consciência histórica e social, o que levou seus gestores a adotar práticas de interação social, levando à conclusão de que o próprio território e suas práticas cotidianas constituiriam o próprio acervo. Trata-se do conceito de "ecomuseu" onde o acervo, afinal, imerso na vida, exerce em plenitude a sua função social. Algo muito parecido com a consciência de que não adianta preservar apenas pequenos nichos, mas que toda a ação humana sobre a face da terra deve ser sustentável e responsável. A idéia do GQF não se sustenta, portanto, na idéia tradicional - inclusive da UNESCO - de uma reserva onde a ação humana é meramente contemplativa ou de redomas de proteção de santuários, mas em uma noção próxima a do ecomuseu: o acervo dentro da realidade das transformações e como um de seus agentes. Parte, é claro, da riqueza e excepcionalidade de seu território, mas não o entende apartado de interesses e pressões e por isso, justamente, necessitando de uma nova instância de proteção, baseada em formas contemporâneas de atuação.

Para a UNESCO, o geopark consiste em um território com limites definidos que apresente sítios geológicos de especial valor científico, combinados com valores ecológicos, arqueológicos, históricos ou culturais inseridos em um processo de desenvolvimento sustentável que fomente projetos educacionais e de valorização do patrimônio cultural local. O processo sustentável a que se refere o conceito diz mais respeito à sustentabilidade do próprio parque - porque o geopark é, sobretudo, um parque, uma reserva - e por isso elege como mecanismos de sustentabilidade os clássicos: turismo (no caso incluindo uma inovação: o "geoturismo"), atividades culturais, educação ambiental e patrimonial. Nesse sentido, o Geopark do Quadrilátero Ferrífero se enquadra perfeitamente bem no conceito, pois conta com sítios geológicos representativos da história geológica da região, associada à evolução global da Terra, e da história da mineração do ouro e do ferro no Brasil, muitos deles com infra-estrutura turística e abertos à visitação.

No entanto, a grande diferença entre o conceito da UNESCO e a iniciativa brasileira se dá em dois pontos, quanto a sua escala e dimensões e quanto a sua inserção na dinâmica territorial (não se trata de uma "reserva"). Esses dois aspectos foram inclusive os que criaram dificuldades para o reconhecimento inicial do GQF na categoria "geoparks", quando da sua primeira visita de seus auditores, em 2011 e que acabou por gerar recomendações quanto à redução da área inicialmente proposta. 
A iniciativa de criação de um geopark dessa natureza partiu, em 2011, de um órgão assessor do Governo Estadual, o Polo de Excelência Mineral e Metalúrgico, tendo como gerente executivo o engenheiro de minas Renato Ciminelli, também seu primeiro coordenador, que percebeu ali a oportunidade da instituição de um geopark como uma iniciativa indutora de uma frente popular de participação na construção de novos futuros para a região. $\mathrm{Na}$ realidade, a proposta teve seu fundamento alguns anos antes, em 2007, quando do lançamento do Programa Pólo de Inteligência para a Mineração e Metalurgia, o qual condicionava a competitividade e sustentabilidade do setor às aspirações das comunidades locais, estabelecendo o Geopark como o instrumento de interlocução participativa com o território minerador. Pouco afetas a inovações do staus quo, grande parte das empresas de mineração e do setor agropecuário criaram resistência ao programa, um por pouco por prevenção, um pouco por desconhecimento, mas, sobretudo, por acreditarem que a criação de um parque deste tipo implicaria na criação de novas unidades de conservação ou restrição de atividades. Muito realisticamente, mesmo porque não há como se criar outro agente de governança transversal a tantos municípios, o governo tentou minimizar esses temores, reforçando o foco do desenvolvimento sustentável ligado à cultura e ao turismo, principalmente voltado ao reaproveitamento de áreas pós-mineradas, criando novas oportunidades para empreendedores locais, a exemplo da Mina do Lousal, Portugal, onde se verifica uma boa integração dessas atividades mesmo na mina ainda em operação. Em face desses temores - e com as pressões deles derivadas - o programa perdeu força no âmbito governamental, mas como já se tornara uma realidade institucional, para sua sobrevivência buscou-se alternativas na sua grande estrutura interna de suporte, a qual abrigava várias instituições fundadoras, dentre elas universidades, instituições de desenvolvimento científico e órgãos governamentais reguladores.

O seu sistema de gestão é composto por Comitê Gestor, pelo Instituto Quadrilátero e pelos sítios que são geridos independentemente. A função do Comitê Gestor é estabelecer e monitorar as diretrizes de instalação e funcionamento do Geopark e de apoiar a gestão global do Geopark através de suas Câmaras Técnicas. Por sua vez, o Instituto Quadrilátero se apresenta como uma entidade privada sem fins lucrativos e como uma Organização da Sociedade Civil de Interesse Público - OSCIP, qualificando-a a atuar também como parceira de projetos governamentais. O Instituto é responsável pela gestão do Geopark e dos seus termos 
de parceria e tem como objetivo desenvolver e promover ações ligadas ao desenvolvimento territorial integrado do Quadrilátero Ferrífero em bases sociais, econômicas, culturais e ambientais sustentáveis. O Geopark QF Operações valida os acordos de cooperação com as instituições gestoras dos sítios, apóia todas as atividades de implantação e operacionalização do Geopark, inclusive com a captação de recursos no Brasil e exterior.

A alternativa GQF se insere, portanto, como uma resposta de uma região tradicionalmente mineradora em construir soluções que modifiquem o quadro atual dicotômico e fechado das relações entre a mineração e a sociedade.

\subsection{A necessidade de uma abordagem integrada da paisagem cultural do Quadrilátero Ferrífero}

Do exame dos casos apresentados, depreende-se que a ação mineradora se apresenta quanto à cultura, o patrimônio e a paisagem cultural - como a deusa hindu Shiva, com uma face criadora e uma face destruidora e, mais do que isso, com uma alternância entre elas. Em alguns casos, como verificaremos mais adiante, a ação destruidora pode ensejar um novo momento criador.

A mineração dos séculos XVII e XVIII em Minas Gerais - e mesmo a do século XIX - possibilitou a criação de núcleos urbanos especiais e de um patrimônio cultural riquíssimo e, embora seus métodos exploratórios também gerassem cicatrizes ambientais, a escala dos impactos era muito menor do que a exploração mineraria do século XX, quando ela se tornou, a partir da Revolução Industrial, uma atividade de indústria. Quando as condicionalidades industriais estão no cerne do desenvolvimento territorial e comunitário elas são as formadoras de fortes símbolos de identidade e memória para as comunidades nascidas em seu entorno. O cotidiano dos grupos sociais que trabalham e habitam tais espaços vai se registrando no espaço físico quer por seu labor industrial quer pelo suporte urbano que se constitui como suporte a essas atividades. As expressões físicas geradas nessas localidades industriais, por sua vez, quando simbolicamente apropriadas pela cultura, constituem-se em patrimônio industrial. Sabemos que a história da indústria e das tecnologias é uma história feita especialmente de avanços que constantemente canibalizam o passado, implicando em uma história de substituições constantes de práticas, de produtos e técnicas, as quais vão gerando complexos industriais 
que vão se tornando obsoletos, sendo abandonados, esquecidos ou mesmo destruídos, acarretando em enormes áreas abandonadas nas cidades e regiões urbanas. No caso da indústria da mineração, esses aspectos são agravados pela escala destrutiva da paisagem por ela empregada em sua atividade exploratória. É paradoxal que a mesma atividade criadora se torne um agente tão destruidor.

Sob o aspecto da destruição, já vimos que além das grandes alterações causadas à paisagem, existem outras, que impactam substancialmente as relações territoriais. Quanto a esse aspecto, verifica-se o aumento da influência do poder corporativo na relação da atividade da mineração com o território, não só por suas características de atividade concentradora e geradora de grande número de empregos - em um tempo finito e determinado - mas também porque a aquisição de áreas no entorno imediato onde atuam tornou-se prática comum das mineradoras, resultando em verdadeiros latifúndios. Sua presença hegemônica faz com que as empresas mineradoras tenham grande poder de decisão sobre os usos futuros do território, influindo não apenas nos aspectos socioeconômicos - dos quais os municípios são extremamente dependentes - como também nas relações identitárias das comunidades locais.

Por outro lado, muitas dessas comunidades - algumas delas originárias de núcleos mineradores setecentistas - emergem como atores relevantes no jogo de interesses e conflitos que se instaura em razão das formas diversificadas de ocupar e utilizar o solo urbano e rural, na construção de suas identidades e valores e na importância atribuída à paisagem local, aos remanescentes ambientais de relevância para a preservação, bem como às áreas de recarga hídrica e aquíferos.

Como resultado desse jogo, como possível ponto criativo para o futuro, estamos buscando um resgate do papel articulador e regulador do Estado, este indispensável na gestão do território, em contraste com a timidez de sua atuação, mais concentrada no viés regulatório, verificada hoje. Embora o Brasil possua uma legislação exemplar, não se consegue, na prática, contemplar toda complexidade das relações territoriais e do processo de fechamento de mina numa visão sistêmica e global, articulando os aspectos ambientais, sociais, econômicos e culturais. No âmbito político, a articulação entre as diversas instâncias e setores governamentais é frágil, dificultando o diálogo e a efetividade nas discussões, a implementação desses planos e ações relacionadas à reintegração de áreas 
antes degradadas, por meio de um planejamento urbano e regional integrado. Percebese, claramente, que apenas ações de viés regulatório não têm dado conta dos problemas gerados pela mineração, sobretudo porque as empresas ainda detém grande autonomia sobre as áreas mineradas.

Ações recentes têm sinalizado para uma nova confluência criadora entre mineração, paisagem e patrimônio cultural. Essas ações se referem tanto ao potencial dos "restos" deixados pela atividade mineradora quanto pelos novos significados por ela criados. Do ponto de vista de estudos prospectivos, entendemos que seria importante a análise da paisagem do Quadrilátero Ferrífero para compreender como sua exploração, apropriação poderia se realizar em bases sustentáveis. Para tanto, estamos desenvolvendo trabalho baseado no processo denominado Geodesign, que busca identificar uma "essência da paisagem" para dar suporte a decisões sobre o território.

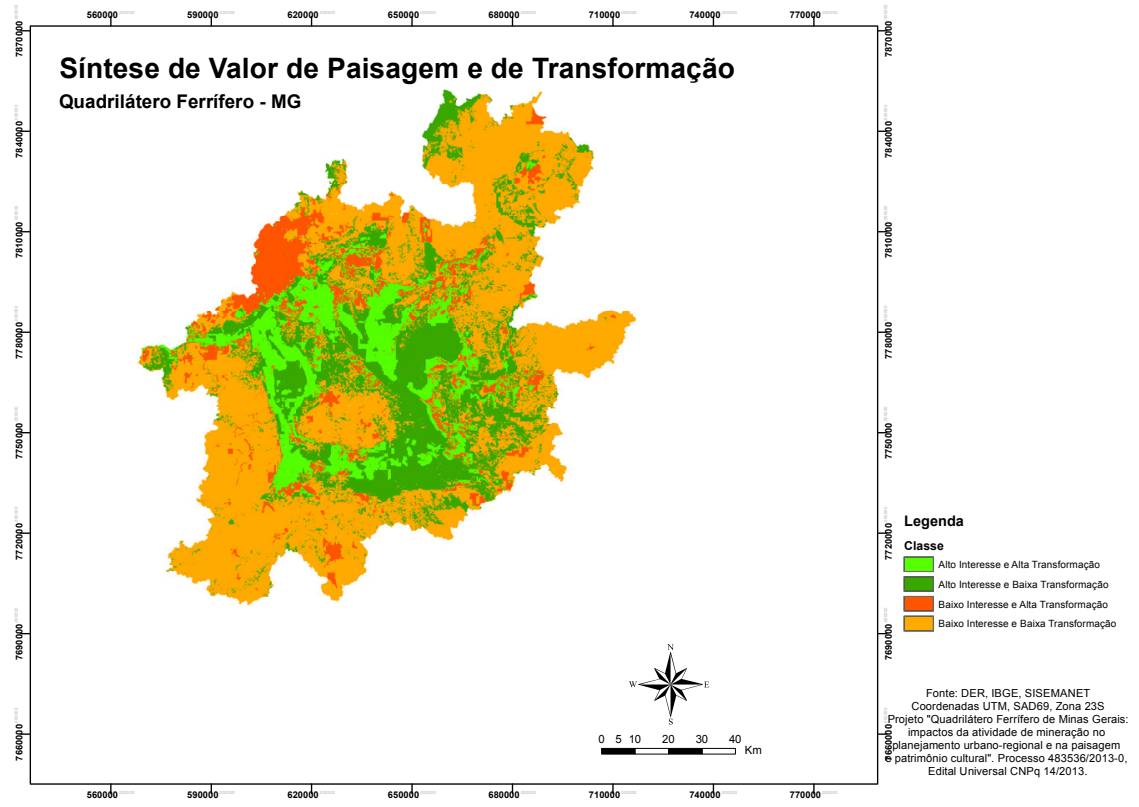


A metodologia proposta por Carl Steinitz se organiza a partir de seis questões interativas baseadas em mapas onde questões especiícas estão georeferenciadas, sendo as três primeiras relativas à descrição e análise da area em estudo e as subsequentes relativas às intervenções necessárias e/ou desejadas:

- Como a area em estudo pode ser descrita?

- Como é operada a area em estudo?

- A area em estudo está sendo bem operada?

- Como a area em estudo pode ser alterada?

- Que diferenças as mudanças propostas podem causar?

- Como a area em estudo pode ser alterada?

Até o momento temos trabalhado apenas nas três primeiras questões, tentando compreender a região em suas características geomorfológicas, antrópicas e de potenciais, identificando entre outras coisas, os impactos da urbanização, as medidas de controle por parte do Estado e a construção de sua significância cultural para estabelecimento de unidades geomorfológicas e culturais, além da identificação de problemas típicos para, no future, chegarmos a um "Plano Territorial para transformação e proteção da paisagem". 


\section{REFERÊNCIAS BIBLIOGRÁFICAS}

ACCIOLY, S. M. L. (2012). "Uso Futuro de Áreas Mineradas e o Meio Urbano: O Caso de Águas Claras". Belo Horizonte: Dissertação (Mestrado em Ambiente Construído e Patrimônio Sustentável) - Escola de Arquitetura da Universidade Federal de Minas Gerais.

BERTRAND, G.; BERTRAND, C. (2002). “Une Géographie Traversière. L'environnement à Travers Territoires et Temporalités". Paris : Éditions Arguments.

BOSREDON, P.; CARSALADE, F. L. (2012). "Culture, patrimoine et développement métropolitain : les exemples du bassin minier du Nord-Pas de Calais (France) et du quadrilatère ferreux du Minas Gerais (Brésil)". São Paulo: Construire la métropole contemporaine Dialogues Brésil - France.

CAMPOS, F. R. L. (2012). “Miguel Burnier: o lugar em fragmentação”. Conselheiro Lafaiete: UFMG.

CARSALADE, F. L. (2005). "Desenho Contextual - uma abordagem fenomenológico-existencial ao problema da intervenção ems lugares especiais feitos pelo homem". Salvador: Tese (programa de Pósgraduação em Arquitetura e Urbanismo/UFBa).

CARSALADE, F. L. (2005). "Culture as a methodological key. City \& Time”. CECI/ UFPe, no. 2, vol. 1. www.ct.ceci-br.org/

CARSALADE, F. L. (2012). Mineração em Minas Gerais, território e paisagem cultural. I Seminário Internacional de Reconversão de Territórios, Belo Horizonte, 1 a 5/10.

CARSALADE, F. L.; CRESPO, J. (2013). "Paisagens mineiro-industriais, território e patrimônio cultural: O caso de Miguel Burnier, MG, Brasil". Anais do II Encontro Projeto ARCUS, Lille.

CERTEAU, M. (1999). A invenção do cotidiano - Artes de Fazer, Petrópolis, Vozes.

FARIAS, C. E. G. (2002). "Mineração e meio ambiente no Brasil”. [S.I:CGEE/ PNUD]. Relatório preparado para o CGEE/PNUD. Disponível em: <http://www.scribd.com/doc/52441018/2/CARACTERISTICASGERAIS-DA-MINERACAO-NO-BRASIL-E-O-MEIO >. Acesso em: 20 maio 2011.

HAESBAERT, R. (2002). “Concepções de território para entender a desterritorialização”. Rio de Janeiro: In: SANTOS, M.; Becker, B. Território, territórios: ensaios sobre o ordenamento territorial. Lamparina Editora. p. 17-39. 
INSEE, (2011). "Les espaces du Nord-Pas-de-Calais, Trajectoires, enjeux et devenir, Dynamiques démographiques - Fascicule 1", Dossiers Profils n¹04.

LYNCH, K. (2005). "A Imagem da Cidade". São Paulo: Martins Fontes.

LÓPEZ MEZA, M. I.; BUSTAMENTE, L. P. (2013). Investigación e iniciativas de revalorización del patrimonio minero en Chile. In: AJA, Agustin Hernandez e LÓPEZ MEZA, Maria Isabel (org.). Reutilización Sostenible del Espacio Minero. Madrid: Instituto Juan de Herrera. P. 59 a 71.

MILLER, W. R. (2012). Introducing Geodesign: The Concept Director of GeoDesign Services. Esri Press, Redlands.

MINAS GERAIS. (2009). Secretaria de Estado de Ciência Tecnologia e Ensino Superior de Minas Gerais. Polo de Excelência Mineral e Metalúrgico Dossiê de candidatura à Rede Mundial de Geoparks - UNESCO: Proposta de criação do geopark Quadrilátero Ferrifero. Belo Horizonte.

MINAS GERAIS. (2012). Secretaria de Desenvolvimento Regional e Urbano. Banco de Notícias. Governo de Minas anuncia início do Plano Regional Estratégico do Norte de Minas. Disponível em: http://www.urbano.mg.gov.br/banco-de-noticias/630-governo-de-minas-anuncia-inicio-do-plano-regionalestrategico-do-norte-de-minas, acesso em 22/07.

MINERAÇOES BRASILEIRAS REUNIDAS; BRANDT MEIO AMBIENTE. (2001). Plano de fechamento: Mina de Águas Claras. Nova Lima: Minerações Brasileiras Reunidas; BRANDT Meio Ambiente; dez. Relatório. v. 1.

MORAES, F. B. de. (2006). "A rede urbana das Minas coloniais: na urdidura do tempo e do espaço". São Paulo: Tese (Programa de Pós-Graduação em Arquitetura e Urbanismo),v. I, II e III.

MOURA, A. C. M. (2007). Reflexões metodológicas como subsídio para estudos ambientais baseados em Análise de Multicritérios. XIII Simpósio de Sensoriamento Remoto, p. 2899-2906.

PARANHOS, R. R. A. (2012). "Recuperação de áreas degradadas pela mineração em regiões de interesse patrimonial". Dissertação (Mestrado em Arquitetura e Urbanismo) - Escola de Arquitetura da Universidade Federal de Minas Gerais, Belo Horizonte.

PARIZZI, G. M., Moura, A. C. M., Memória, E., Magalhães, D. M. (2010). Mapa de unidades geotécnicas da Região Metropolitana de Belo Horizonte. PDDI (Plano Diretor Integrado da Região Metropolitana de Belo Horizonte - Relatório Técnico) 
PEREIRA LEITE, M. A. F. (1994). "Destruição ou desconstrução? Questões da paisagem e tendências de regionalização". São Paulo: Hucitec.

RAPOPORT, A.n (1972). "Vivenda y Cultura”. Barcelona: Gustavo Gili.

RIBEIRO, M. T. F.; MILANI, C. R. S. (2009). "Compreendendo a complexidade socioespacial contemporânea: o território como categoria de diálogo interdisciplinar". Salvador: EDUFBA.

SANTOS, M. (1994). "O retorno do território". São Paulo: In: Território: globalização e fragmentação. Hucitec/Anpur (15-20).

SANTOS, M.; SILVEIRA, M. L. (2010). "O Brasil: território e sociedade no início do século XXI". Rio de Janeiro: Record, 13. ed.

SISTEMA DE INFORMAÇÕES GEOGRÁFICAS PARA MINERAÇÃO Disponivel em: <http://www2.siam. mg.gov.br/webgis/mineracao/viewer.htm>. Acesso em ago./2012.

SOLINÍS, G. (2009). "O que é o território ante o espaço?" In: RIBEIRO, Maria Teresa Franco; MILANI, Carlos Roberto Sanchez. (org.). Compreendendo a complexidade socioespacial contemporânea: o território como categoria de diálogo interdisciplinar. Salvador: EDUFBA, p. 264-289.

STEINITZ, C. (2012). "A Framework for Geodesign: Changing Geography by Design". Esri Press, Redlands 